\title{
PENGARUH PROLANIS TERHADAP PENINGKATAN KUALITAS HIDUP PENDERITA HIPERTENSI DI PUSKESMAS ANTANG MAKASSAR
}

\author{
Lilik Meilany \\ Sekolah Tinggi Ilmu Kesehatan Panakkukang Makassar \\ email : lilikmeilany@gmail.com
}

\author{
Patria Artha Journal of Nursing Science \\ 2021. Vol. 5(1), \\ Issn: 25495674 \\ e-issn: 25497545 \\ Reprints and permission: \\ http://ejournal.patria-artha.ac.id/index.php/jns
}

\begin{abstract}
Abstrak
Tujuan: untuk mengetahui pengaruh Prolanis terhadap kulaitas hidup penderita hipertensi di Puskesmas Antang. Jenis penelitian adalah penelitian quasi eksperiment dengan rancangan non-randomized pretest-post test design menggunakan instrument WHOQOL-BREF. Sampel dipilih menggunakan teknik Purposive Sampling. Hasil penelitian menunjukkan bahwa ada pengaruh Prolanis terhadap kesehatan fisik penderita $(p=0,001)$, ada pengaruh Prolanis terhadap kondisi psikologis penderita $(p=0,001)$, ada pengaruh Prolanis terhadap hubungan sosial penderita $(p=0,001)$, ada pengaruh Prolanis terhadap kondisi lingkungan penderita $(p=0,001)$, hasil uji beda rata-rata skor kualitas hidup antara kelompok intervensi dan kelompok non intervensi diperoleh nilai $p=0,000 \quad(p<0,05)$ artinya ada perbedaan tingkat kesehatan fisik sebesar 16,36, ada perbedaan kondisi psikologis sebesar 19,2, ada perbedaan hubungan sosial sebesar 15,6, ada perbedaan kondisi lingkungan sebesar 16,84. Disarankan kepada pihak puskesmas agar lebih meningkatkan pelayanan bagi penderita penyakit kronis sebagai upaya preventif dalam penanggulangan penyakit kronis, dan promotif sehingga Prolanis juga dapat diterapkan di fasyankes primer lainnya.
\end{abstract}

Kata kunci: Prolanis, Hipertensi, Puskesmas, Antang

\section{PENDAHULUAN}

Hipertensi adalah suatu keadaan dimana seseorang mengalami peningkatan tekanan darah di atas normal yang ditunjukkan oleh angka sistolik (bagian atas) dan angka diastolik (bagian bawah) pada pemeriksaan tensi darah menggunakan alat pengukur tekanan darah baik berupa cuff air raksa (sphygmomanometer) ataupun alat digital lainnya. Menurut WHO, batas tekanan darah normal adalah bila tekanan darah kurang dari 130/85 mmHg, sedangkan bila lebih dari $140 / 90 \mathrm{mmHg}$ dinyatakan sebagai hipertensi (Shadine, 2010).

Penderita hipertensi sebanyak 1 milyar orang di dunia pada tahun 2011 dan dua per-tiga diantaranya berada di negara berkembang yang berpenghasilan rendahsedang. Bila tidak dilakukan upaya yang tepat jumlah ini akan terus meningkat, dan diprediksi oleh WHO jumlah penderita hipertensi pada tahun 2025 meningkat menjadi $29 \%$ atau 1,6 miliar orang di seluruh dunia menderita hipertensi (Depkes, 2008)

Menurut data Riskesdas tahun 2013 lebih dari $25,8 \%$ orang Indonesia yang berusia di atas 18 tahun menderita penyakit darah tinggi (hipertensi). Prevalensi kasus hipertensi tertinggi tahun 2013 di daerah Bangka Belitung yaitu sebesar 30,9\% dan yang terendah adalah Papua yaitu 16,8\%. Sedangkan di daerah Sulawesi Selatan menduduki peringkat ke- 8 kasus hipertensi dengan prevalensi sebesar 28,1\% (Riskesdas, 2013).

Berdasarkan data yang diperoleh dari Pengelola PTM Bidang P2PL Dinas Kesehatan Kota Makassar prevalensi hipertensi tahun 2013 sebanyak 8.621, meningkat tahun 2015 yaitu 10.921 kasus. Hipertensi menduduki urutan ke-1 dalam 10 (sepuluh) jenis penyakit penyebab utama kematian semua golongan umur, 
pada tahun 2013 sebanyak 234 kematian dan tahun 2015 sebanyak 278 kasus kematian (Dinkes Kota Makassar, 2015).

Puskesmas Antang merupakan salah satu puskesmas berada dalam wilayah kecamatan di kota Makassar dengan prevalensi Hipertensi tahun 2015 sebanyak 651 penderita dari 2453 total kunjungan. Dari data diatas dapat dilihat bahwa masih tinggi jumlah kasus hipertensi di wilayah tersebut (Profil Puskesmas Antang, 2015).

Berdasarkan dampak dari penyakit hipertensi pada keadaan fisik, psikologis, sosial dan lingkungan disimpulkan bahwa hidup dengan hipertensi mempunyai pengaruh negatif terhadap kualitas hidup penderita walaupun dengan tanpa kompilkasi (Skevington, 2004).

Berbagai upaya pengendalian hipertensi telah dilakukan antara lain dengan penyuluhan tentang pola makan pada penderita hipertensi, pemberian jus buah belimbing dan mentimun terhadap penurunan tekanan darah, latihan relaksasi dan senam bugar lansia serta konseling terhadap kualitas hidup penderita hipertensi.

Jurnal dari Hayes DK, Denny $\mathrm{CH}$, Keenan NL, Croft JB, Greenlund KJ (2008) menyebutkan bahwa 30\% responden yang menderita hipertensi cenderung menyebutkan bahwa dirinya memiliki status kesehatan yang buruk dibandingkan dengan yang tidak hipertensi. Status kesehatan yang buruk mengindikasikan kualitas hidup tidaklah baik.

Studi yang dilakukan Sentana (2015) dengan metode Eksperimen menunjukkan ada perubahan pengetahuan dan sikap yang signifikan sebelum dan sesudah pemberian bimbingan konseling tentang perawatan diri masing-masing dengan skor $\mathrm{p}(0,001)<0,05$, ada perubahan tindakan yang signifikan sebelum dan sesudah pemberian bimbingan konseling tentang perawatan diri hipertensi dengan skor $\mathrm{p}$ $0,003<0,05$, dan ada perubahan tekanan darah yang signifikan sebelum dan sesudah pemberian bimbingan konseling tentang perawatan diri hipertensi dengan skor $\mathrm{p}$ $(0,001)<0,05$. Hasil penelitian ini menunjukkan bahwa bimbingan konseling tentang perawatan diri perlu dilakukan sehingga dapat mengontrol tekanan darah pasien.

Program kesehatan yang bersifat preventif, promotif, kuratif, dan rehabilitatif secara parallel diskor sangat penting dalam pengendalian penyakit kronis seperti hipertensi. Pemerintah melalui Kementerian Kesehatan bekerjasama dengan BPJS Kesehatan berusaha terus meningkatkan pelayanannya dengan membuat suatu kebijakan yaitu Prolanis atau Program Pengelolaan Penyakit Kronis (Adrita, 2015).

Prolanis menurut Jordan (2007), merupakan pengelolaan yang lebih baik pada penyakit kronis dimana lebih mengutamakan kemandirian pasien dan program ini juga sebagai upaya promotif serta preventif dalam penanggulangan penyakit kronis.

Penelitian ini bertujuan untuk mengetahui pengaruh Prolanis melalui konseling medis terhadap kualitas hidup penderita hipertensi di wilayah Puskesmas Antang.

\section{Metode penelitian}

Lokasi penelitian adalah Puskesmas Antang. Jenis penelitian yang digunakan adalah penelitian quasi eksperiment dengan rancangan non-randomized pretest-post-test design menggunakan instrument WHOQOL-BREF. Uji statistik yang digunakan adalah uji Wilcoxon dan uji Mann-Whitey.

\section{HASIL}

a. Hasil

Tabel 1 menunjukkan bahwa skor rata-rata domain 1 untuk kelompok intervensi adalah 18,35 mengalami peningkatan nilai mean saat post test menjadi 22,45, pada kelompok non intervensi nilai mean adalah 17,55 mengalami pengingkatan nilai mean menjadi 18,90. Untuk skor rata-rata domain 2 kelompok intervensi adalah 14,60 mengalami peningkatan nilai mean menjadi 19,85 sedangkan pada kelompok non intervensi nilai rata-rata saat pre test adalah 14,05 mengalami peningkatan namun tidak signifikan menjadi 15,45. Untuk domain 3 pada saat pre test kelompok intervensi adalah 7,10 
mengalami peningkatan nilai rata-rata menjadi 10,4. Pada kelompok non intervensi nilai rata-rata saat pre test adalah 6,80 mengalami peningkatan nilai mean menjadi 8,00. Domain 4 kelompok intervensi adalah 17,85 mengalami peningkatan nilai rata-rata menjadi 23,05 , kelompok non intervensi mengalami peningkatan nilai rata-rata namun tidak signifikan yaitu 16,85 menjadi 19,25.

Tabel 1.

Distribusi responden berdasarkan skor kualitas hidup saat pre test dan post test kelompok intervensi dan kelompok non

\begin{tabular}{llcc}
\multicolumn{3}{c}{ intervensi } \\
\hline Kelompok & Nilai & \multicolumn{2}{c}{ Skor Domain 1 } \\
& Statistik & (Kesehatan Fisik) & S \\
& & Pre Test & Post \\
& & & Test \\
\hline Intervensi & Minimum & 15 & 18 \\
& Maksimum & 21 & 25 \\
& Mean & 18,35 & 22,46 \\
& SD & 1,87 & 1,88 \\
\hline Non & Minimum & 15 & 15 \\
Intervensi & Maksimum & 19 & 21 \\
& Mean & 17,55 & 18,90 \\
& SD & 1,43 & 1,41 \\
\hline Kelompok & Nilai & Skor Domain 2 \\
& Statistik & (Kondisi Psikologi) \\
\hline & & Pre Test & Post \\
& & & Test \\
\hline
\end{tabular}

\begin{tabular}{|c|c|c|c|}
\hline \multirow[t]{4}{*}{ Intervensi } & Minimum & 12 & 17 \\
\hline & Maksimum & 18 & 21 \\
\hline & Mean & 14,60 & 19,85 \\
\hline & $\mathrm{SD}$ & 2,04 & 1,14 \\
\hline Non & Minimum & 12 & 13 \\
\hline \multirow[t]{3}{*}{ Intervensi } & Maksimum & 17 & 17 \\
\hline & Mean & 14,05 & 15,45 \\
\hline & SD & 1,76 & 1,28 \\
\hline \multirow[t]{2}{*}{ Kelompok } & $\begin{array}{l}\text { Nilai } \\
\text { Statistik }\end{array}$ & \multicolumn{2}{|c|}{$\begin{array}{c}\text { Skor Domain } 3 \\
\text { (Hubungan Sosial) }\end{array}$} \\
\hline & & Pre Test & $\begin{array}{l}\text { Post } \\
\text { Test }\end{array}$ \\
\hline \multirow[t]{4}{*}{ Intervensi } & Minimum & 6 & 8 \\
\hline & Maksimum & 9 & 12 \\
\hline & Mean & 7,1 & 10,4 \\
\hline & SD & 0,91 & 1,14 \\
\hline Non & Minimum & 6 & 6 \\
\hline \multirow[t]{3}{*}{ Intervensi } & Maksimum & 9 & 10 \\
\hline & Mean & 6,8 & 8 \\
\hline & SD & 0,89 & 1,3 \\
\hline Kelompok & $\begin{array}{l}\text { Nilai } \\
\text { Statistik }\end{array}$ & \multicolumn{2}{|c|}{$\begin{array}{c}\text { Skor Domain } 4 \\
\text { (Kondisi } \\
\text { Lingkungan) }\end{array}$} \\
\hline
\end{tabular}

\begin{tabular}{lccc}
\hline & Pre Test & $\begin{array}{c}\text { Post } \\
\text { Test }\end{array}$ \\
\hline Intervensi & Minimum & 15 & 20
\end{tabular}

\begin{tabular}{llcc}
\hline & Maksimum & 20 & 25 \\
& Mean & 17,85 & 23,05 \\
& SD & 1,79 & 1,43 \\
\hline Non & Minimum & 15 & 15 \\
Intervensi & Maksimum & 19 & 22 \\
& Mean & 16,85 & 19,25 \\
& SD & 1,46 & 2,31 \\
\hline
\end{tabular}

Sumber Data : Data Primer 2017

Tabel 2.

Analisis Skor Kesehatan Fisik antara sebelum dan sesudah intervensi pada kelompok intervensi di Puskesmas Antang Makassar

\begin{tabular}{lccc}
\hline Variabel & $\mathrm{n}$ & $\begin{array}{c}\text { Mean } \\
\text { Rank }\end{array}$ & P value \\
\hline Domain 1 sebelum & 20 & 0,00 & 0,001 \\
Domain 1 sesudah & 20 & 10,50 & \\
Sumber Data : Data Primer & $\mathbf{2 0 1 7}$ & \\
\multicolumn{4}{l}{ Hasil analisis skor } \\
kesehatan fisik
\end{tabular}

pada tabel 2, dengan uji Wilcoxon diperoleh nilai $p=0,001(p<0,05)$ beda nilai (mean) antara pre test dan post test sebesar 4,1 menunjukkan bahwa ada pengaruh konseling Prolanis terhadap kesehatan fisik responden.

Tabel 3.

Analisis Skor Kondisi Psikologis antara sebelum dan sesudah intervensi pada kelompok intervensi di Puskesmas Antang Makassar

\begin{tabular}{llcl}
\hline Variabel & $\mathrm{n}$ & Mean Rank & $\mathrm{P}$ value \\
\hline Domain 2 sebelum & 20 & 0,00 & 0,001 \\
Domain 2 sesudah & 20 & 10,50 & \\
\hline
\end{tabular}

Sumber Data : Data Primer 2017

Hasil analisis skor kondisi psikologis pada tabel 3, dengan uji Wilcoxon diperoleh nilai $p=0,001(p<0,05)$ beda nilai (mean) antara pre test dan post test sebesar 5,25 menunjukkan bahwa ada pengaruh konseling Prolanis terhadap kondisi psikologis responden.

Tabel 4.

Analisis Skor Hubungan Sosial antara sebelum dan sesudah intervensi pada kelompok intervensi di Puskesmas Antang Makassar

\begin{tabular}{lccl}
\hline Variabel & $\mathrm{n}$ & Mean Rank & $\begin{array}{l}\mathrm{P} \\
\text { value }\end{array}$ \\
\hline Domain 3 sebelum 20 & 0,00 & 0,001 \\
Domain 3 sesudah & 20 & 10,50 & \\
\hline Sumber Data : Data Primer 2017
\end{tabular}


Hasil analisis skor kondisi psikologis pada tabel 4, dengan uji Wilcoxon diperoleh nilai $p=0,001(p<0,05)$ beda nilai (mean) antara pre test dan post test sebesar 3,3 menunjukkan bahwa ada pengaruh konseling Prolanis terhadap hubungan sosial responden.

Tabel 5.

Analisis Skor Hubungan Sosial antara sebelum dan sesudah intervensi pada kelompok intervensi di Puskesmas Antang Makassar

\begin{tabular}{llrl}
\hline Variabel & $\mathrm{n}$ & $\begin{array}{c}\text { Mean } \\
\text { Rank }\end{array}$ & $\begin{array}{l}\mathrm{P} \\
\text { value }\end{array}$ \\
\hline Domain 4 sebelum & 20 & 0,00 & 0,001 \\
Domain 4 sesudah & 20 & 10,50 & \\
\hline Sumber Data : Data Primer & 2017 &
\end{tabular}

Sumber Data : Data Primer 2017

Hasil analisis skor kondisi psikologis pada tabel 5, dengan uji Wilcoxon diperoleh nilai $p=0,001(p<0,05)$ beda nilai (mean) antara pre test dan post test sebesar 5,2 menunjukkan bahwa ada pengaruh konseling Prolanis terhadap kondisi lingkungan responden.

Analisis perbedaan rata-rata skor Domain 1,2,3 dan 4 penderita Hipertensi antara kelompok intervensi dengan kelompok non intervensi.

Tabel 6.

Analisis Perbedaan Skor Kesehatan Fisik antara Kelompok Intervensi dan

Kelompok Non Intervensi saat pre test dan post test di Puskesmas Antang dan Puskesmas Maradekaya

\begin{tabular}{|c|c|c|c|c|}
\hline \multirow[b]{2}{*}{$\begin{array}{l}\text { nilai } \\
\text { statis } \\
\text { tik }\end{array}$} & \multicolumn{2}{|l|}{ Pre-test } & \multicolumn{2}{|c|}{ Post-test } \\
\hline & $\begin{array}{l}\text { Kelompo } \\
\text { k } \\
\text { Interven } \\
\text { si }\end{array}$ & $\begin{array}{l}\text { Kelompo } \\
\text { k Non } \\
\text { Interven } \\
\text { si }\end{array}$ & $\begin{array}{l}\text { Kelomp } \\
\text { ok } \\
\text { Interve } \\
\text { nsi }\end{array}$ & $\begin{array}{l}\text { Kelom } \\
\text { pok } \\
\text { Non } \\
\text { Interve } \\
\text { nsi }\end{array}$ \\
\hline $\mathrm{N}$ & 20 & 20 & 20 & 20 \\
\hline $\begin{array}{l}\text { Mean } \\
\text { Rank }\end{array}$ & 23,02 & 17,98 & 28,68 & 12,32 \\
\hline $\begin{array}{l}p \\
\text { value }\end{array}$ & 0,164 & & 0,000 & \\
\hline
\end{tabular}

\section{Sumber : Data Primer}

Pada tabel 6 hasil uji statistik menggunakan uji Mann-Whitney diperoleh nilai $\mathrm{p}=0,000(p<0,05)$ menunjukkan beda skor yang signifikan sebesar 16,36 , berarti ada perbedaan kualitas hidup berdasarkan kesehatan fisik antar kelompok intervensi dan kelompok non intervensi.

Tabel 7.

Analisis Perbedaan Skor Kondisi

Psikologis Kelompok Intervensi dan Kelompok Non Intervensi saat pre test dan post test di Puskesmas Antang dan Puskesmas Maradekaya

\begin{tabular}{lllll}
\hline \multirow{2}{*}{$\begin{array}{l}\text { nilai } \\
\text { statistik }\end{array}$} & Pre-test & \multicolumn{3}{c}{ Post-test } \\
\cline { 2 - 5 } & $\begin{array}{l}\text { Kelompok } \\
\text { Intervensi }\end{array}$ & $\begin{array}{l}\text { Kelompok } \\
\text { Intervensi }\end{array}$ & $\begin{array}{l}\text { Kelompok } \\
\text { Intervensi }\end{array}$ & $\begin{array}{l}\text { Kelompok } \\
\text { Intervensi }\end{array}$ \\
\hline $\mathrm{N}$ & 20 & 20 & 20 & 20 \\
$\begin{array}{l}\text { Mean } \\
\text { Rank }\end{array}$ & 22,72 & 18,28 & 30,10 & 10,90 \\
\hline$p$ value & 0,221 & & 0,000 & \\
\hline
\end{tabular}

Sumber : Data Primer

Pada tabel 7 hasil uji statistik menggunakan uji Mann-Whitney diperoleh nilai $p=0,000(p<0,05)$ menunjukkan beda skor yang signifikan sebesar 19,2, berarti ada perbedaan kualitas hidup berdasarkan kondisi psikologis antar kelompok intervensi dan kelompok non intervensi.

Tabel 8.

Analisis Perbedaan Skor Hubungan Sosial Kelompok Intervensi dan Kelompok Non Intervensi saat pre test dan post test di Puskesmas Antang dan Puskesmas Maradekaya

\begin{tabular}{|c|c|c|c|c|}
\hline \multirow[b]{2}{*}{$\begin{array}{l}\text { Nilai } \\
\text { statistik }\end{array}$} & \multicolumn{2}{|l|}{ Pre-test } & \multicolumn{2}{|l|}{ Post-test } \\
\hline & $\begin{array}{l}\text { Kelompo } \\
\text { k } \\
\text { Interven } \\
\text { si }\end{array}$ & $\begin{array}{l}\text { Kelompo } \\
\text { k Non } \\
\text { Interven } \\
\text { si }\end{array}$ & $\begin{array}{l}\text { Kelompo } \\
\mathbf{k} \\
\text { Intervens } \\
\mathbf{i}\end{array}$ & $\begin{array}{l}\text { Kelomp } \\
\text { ok Non } \\
\text { Interve } \\
\text { nsi }\end{array}$ \\
\hline $\mathrm{N}$ & 20 & 20 & 20 & 20 \\
\hline $\begin{array}{l}\text { Mean } \\
\text { Rank }\end{array}$ & 22,45 & 18,55 & 28,30 & 12,70 \\
\hline$p$ value & 0,260 & & 0,000 & \\
\hline
\end{tabular}

Sumber : Data Primer

Pada tabel 8 hasil uji statistik menggunakan uji Mann-Whitney diperoleh nilai $\mathrm{p}=0,000(p<0,05)$ menunjukkan beda skor yang signifikan sebesar 15,6, berarti ada perbedaan kualitas hidup berdasarkan hubungan sosial antar kelompok intervensi dan kelompok non intervensi. 
Tabel 9.

Analisis Perbedaan Skor Kondisi Lingkungan Kelompok Intervensi dan Kelompok Non Intervensi saat pre test dan post test di Puskesmas Antang dan Puskesmas Maradekaya

\begin{tabular}{lllll}
\hline \multirow{2}{*}{$\begin{array}{l}\text { nilai } \\
\text { statistik }\end{array}$} & Pre-test & & Post-test \\
\cline { 2 - 5 } & $\begin{array}{l}\text { Kelompok } \\
\text { Intervensi }\end{array}$ & $\begin{array}{l}\text { Kelompok } \\
\text { Non } \\
\text { Intervensi }\end{array}$ & $\begin{array}{l}\text { Kelompok } \\
\text { Intervensi }\end{array}$ & $\begin{array}{l}\text { In } \\
\text { N }\end{array}$ \\
$\begin{array}{l}\text { Mean } \\
\text { Rank }\end{array}$ & 20 & 20 & 20 & 28.88 \\
\hline$p$ value & 0,064 & 17,12 & 28,92 & 1 \\
\hline
\end{tabular}

Sumber : Data Primer

Pada tabel 9 hasil uji statistik menggunakan uji Mann-Whitney diperoleh nilai $p=0,000(p<0,05)$ menunjukkan beda skor yang signifikan sebesar 16,84 , berarti ada perbedaan kualitas hidup berdasarkan kondisi lingkungan antar kelompok intervensi dan kelompok non intervensi.

\section{Pembahasan}

Kesehatan fisik dapat di peroleh melalui aktivitas fisik secara teratur (olahraga), gizi yang baik, dan istirahat yang cukup. Kesehatan fisik berfokus pada tubuh seberapa baik tubuh itu berfungsi dan seberapa baik seseorang merawatnya agar terhindar dari luka dan penyakit baik menular dan tidak menular contohnya seperti penyakit tekanan darah tinggi.

Sebelum terlibat dalam kegiatan konseling dan mendapatkan edukasi, penderita sering mengalami depresi akibat tekanan keluarga, pekerjaan dan ekonomi hingga merasa cemas dan putus asa dalam kehidupan mereka, dan efek dari obat yang dikonsumsi tidak berpengaruh atau memberikan perubahan yang positif terhadap kondisi kesehatan mereka. Bahkan ketika tekanan darah naik mereka mengeluh sering merasa sakit badan sehingga perlu dirujuk ke rumah sakit untuk mendapatkan perawatan medis, selain itu responden juga sering mengeluh merasa cepat lelah karena energy/vitalitas yang kurang untuk beraktivitas sehari-hari. Serta istirahat dan pola tidur yang tidak teratur berdampak pada kualitas hidup penderita hipertensi itu sendiri.

$$
\text { Upaya Prolanis yang }
$$

diselenggarakan oleh BPJS Kesehatan bekerjasama dengan Fasilitas Kesehatan Tingkat Pertama bertujuan mendorong peserta penyandang penyakit kronis mencapai kualitas hidup optimal. Setelah dilakukan konseling, responden rutin mengikuti aktifitas klub seperti senam yang dilaksanakan pihak BPJS bekerjasama K Noesponden mengatakan banyak manfaat Integrigngiperoleh antara lain; mendapatkan 2đambahan pengetahuan dan juga informasi terkait dengan penyakit hipertensi, 12ekanan darah terkontrol, berat badan stabil/ringan, rasa nyeri dan sakit badan berkurang sehingga dapat melakukan aktifitas rutin sehari-hari dan mampu menyelesaikan pekerjaan dengan baik, pola makan teratur dan istirahat/tidur dengan puas bahkan kebutuhan terhadap terapi medis di rumah sakit mulai berkurang karena dengan program ini pasien mendapat pelayanan rujuk balik.

Hasil analisis data menunjukkan bahwa terjadi peningkatan skor rata-rata setelah diberikan konseling sebesar 4 . Hasil uji statistik menggunakan uji Wilcoxon diperoleh nilai $p=0,001 \quad(p<0,05)$ menunjukkan ada perbedaan rata-rata skor kesehatan fisik sebelum dan sesudah intervensi sehingga dapat disimpulkan bahwa ada pengaruh konseling Prolanis terhadap kesehatan fisik penderita hipertensi.

Hal ini ditunjukkan oleh beberapa item pertanyaan yang mengalami peningkatan skor jawaban. Hal ini sejalan dengan penelitian lain yang dilakukan Sentana (2015) metode Eksperimen menunjukkan ada perubahan yang signifikan sebelum dan sesudah pemberian bimbingan konseling tentang perawatan diri masing-masing dengan skor $p(0,001)$ $<0,05$, ada perubahan tindakan yang signifikan sebelum dan sesudah pemberian bimbingan konseling tentang perawatan diri hipertensi dengan skor $p 0,003<0,05$, dan ada perubahan tekanan darah yang signifikan sebelum dan sesudah pemberian bimbingan konseling tentang perawatan diri hipertensi dengan skor $p(0,001)<$ 0,05 .

Berbeda dengan hasil yang diperoleh pada kelompok non intervensi, terjadi peningkatan namun tidak sebaik 
kelompok intervensi. Hal ini serupa dengan penelitian yang dilakukan Tuna (2011) untuk mengetahui keefektifan Konseling Eklektik Untuk Menurunkan Tekanan Darah dan Meningkatkan Kualitas Hidup Pasien Hipertensi dengan instrumen penelitian menggunakan alat Sphygomomanometer dan kuesioner WHOQOL BREF, hasil menunjukan pada skor WHOQOL BREF adanya perbedaan peningkatan kualitas hidup antara kelompok intervensi dan kelompok non intervensi tetapi secara statistik tidak signifikan $\quad(t=1,16$; $p>0,005$ ).

Kondisi fisik dan psikologis seseorang seringkali saling terkait,dari sakit fisik bisa muncul gangguan psikologis, sebaliknya pula, dari gangguan psikologis bisa muncul sakit fisik yang keduanya tentu berdampak terhadap kualitas hidup penderita hipertensi. Responden ketika diawal penelitian dengan kondisi hipertensi berat cenderung mengatakan sedikit menikmati hidup dan sulit untuk berkonsentrasi hal ini disebabkan karena responden sering merasakan felling blue (kesepian, putus asa, cemas dan depresi). Berbagai masalah psikologis ini akan mempengaruhi kemampuan penderita untuk berpartisipasi secara penuh dalam pengobatan dan perawatan dirinya, sehingga akan berdampak terhadap kualitas hidup penderita. Namun setelah diberikan intervensi dalam bentuk konseling dimana setiap berlangsung kegiatan tersebut seluruh responden sangat antusias untuk konsultasi permasalahan yang dialami penderita dan cenderung menimbulkan stress. Hal tersebut sangat memberikan dampak psikologis yang sangat positif kepada peserta. Semangat dan antusiasme peserta untuk secara rutin terlibat dalam kegiatan Prolanis juga tergambar dari keceriaan dan pernyataan para peserta sangat bersyukur dengan kegiatan yang dicanangkan pemerintah melalui program BPJS seperti prolanis.

Hasil analisis perbedaan skor kesehatan psikologi menunjukkan terjadi peningkatan skor hasil uji statistik menggunakan uji Wilcoxon diperoleh bahwa $p=0,001$ $(p<0,05)$ yang dapat disimpulkan ada pengaruh konseling prolanis terhadap kondisi psikologis penderita hipertensi. Upaya Prolanis yang diselenggarakan oleh BPJS Kesehatan bekerjasama dengan Fasilitas Kesehatan Tingkat Pertama bertujuan mendorong peserta penyandang penyakit kronis mencapai kualitas hidup optimal.

Dukungan sosial sangat berpengaruh terhadap kualitas hidup, dimana semakin tinggi dukungan sosial yang diterima, maka semakin tinggi kualitas hidup penderita penyakit jantung pasca serangan jantung. Hitch, dkk (1994) dalam penelitiannya menyatakan bahwa dengan adanya dukungan sosial dari lingkungan sosial, penderita tidak merasa sendiri dalam penderitaannya. Akan tetapi lingkungan sosial akan menjadi pemberi semangat untuk mengeluarkan rasa takutnya dan menolong penderita dalam membangun kembali kepercayaan diri, hal yang sama dikemukakan oleh Smet (1996), menyatakan bahwa dengan dukungan sosial individu akan mendapat pengalaman positif, dan meningkatkan rasa percaya diri serta mampu untuk mengontrol perubahan-perubahan dilingkungannya.

Kepuasan hubungan seksual dan kepuasan dukungan teman tidak ada responden yang menjawab sangat memuaskan dan memuaskan. Hal ini terjadi karena mereka merasa cepat lelah dan kurang bergairah dalam hal hubungan seksual dengan penyakit yang diderita.

Setelah diberi konseling terkait pertanyaan pada domain 3, responden lebih cenderung mudah untuk berinteraksi dengan orang lain, baik dilingkungan tempat tinggal, lingkungan kerja maupun kepada sesame penderita hipertensi mereka saling memberi dukungan untuk tetap semangat meskipun hidup dengan penyakit kronis.

Hasil analisis perbedaan skor hubungan sosial menunjukkan terjadi peningkatan dan hasil uji statistik menggunakan uji Wilcoxon diperoleh bahwa $p=0,001$ $(p<0,05)$ yang dapat disimpulkan ada pengaruh konseling prolanis terhadap hubungan sosial penderita hipertensi.

Domain lingkungan, terkait pertanyaan tentang seberapa sering penderita merasa aman, seberapa sehat lingkungan tempat tinggal, kebutuhan akan uang, dan 
seberapa jauh ketersediaan informasi bagi kehidupan penderita, seberapa puas dengan layanan kesehatan, dan seberapa puas dengan transportasi yg digunakan. Pada saat diawal penelitian dilakukan pretest sebagian besar responden mengungkapkan kehidupan mereka sedikit kurang aman hal ini disebabkan karena penyakit yang mereka derita dan harus mengkonsumsi obat sehingga memungkinkan menimbulkan komplikasi, serta kepuasan dengan layanan kesehatan sebagian besar menjawab tidak puas karena pasien hanya mendapatkan obat untuk menurunkan tekanan, sementara masyarakat mengetahui hipertensi itu merupakan penyakit tidak menular namun dampaknya adalah penyakit ini bisa menimbulkan komplikasi dan berbahaya bahkan sampai menyebabkan kematian.. Akan tetapi ,sebagian besar masyarakat masih belum memahami secara benar cara penanggulangannya.

Hasil analisis perbedaan skor hubungan sosial sebelum dan sesudah intervensi menunjukkan terjadi peningkatan skor saat pre-test nilai mean diperoleh 17,85 menjadi 23,05 saat posttest dan hasil uji statistik menggunakan uji Wilcoxon diperoleh bahwa $p=0,001$ $(p<0,05)$ yang berarti bahwa ada perbedaan skor kesehatan psikologi pada penderita hipertensi antara sebelum dan sesudah intervensi sebesar 5,2, sehingga disimpulkan ada pengaruh konseling prolanis terhadap kondisi lingkungan penderita hipertensi.

Pengaruh prolanis sangat dirasakan manfaatnya oleh responden dimana dengan prolanis penderita yang mengalami tekanan darah tinggi yang tidak bisa ditangani oleh pukesmas, langsung dirujuk ke dokter spesialis untuk mendapatkan perawatan dan setelah mendapatkan pelayanan pasien dirujuk balik ke puskesmas yang merujuk, selain itu dengan adanya prolanis melalui konseling penderita lebih terkontrol baik dari pola makan, pola tidur sehingga mereka merasa lebih nyaman dan menikmati hidup dengan tidak merasa takut, cemas dan putus asa.

Perbedaan rata-rata nilai kualitas hidup penderita hipertensi antara kelompok intervensi dengan kelompok non intervensi dapat dilihat pada perbandingan hasil pretest dan post-test pada kedua kelompok menggunakan uji Mann Whitney, diperoleh hasil uji statistik terhadap kedua kelompok pada saat pre-test nilai $p=0,164 \quad(p>0,05)$ menunjukkan tidak ada perbedaan nilai mean antara kelompok intervensi dan kelompok non intervensi artinya kesehatan fisik penderita hipertensi baik pada kelompok intervensi dan non intervensi sebelum diberikan konseling pada kelompok intervensi tidak berbeda secara signifikan. Namun setelah di berikan konseling prolanis untuk kelompok intervensi sedangkan kelompok non intervensi diberikan leaflet tentang intervensi hasilnya diperoleh nilai $p=0,000$ $(p<0,05)$ menunjukkan terdapat perbedaan yang signifikan skor kesehatan fisik antara penderita kelompok intervensi dengan non intervensi sebesar 16,36.

Hal sama juga terjadi pada kondisi psikologis dimana perbandingan hasil pretest dan post-test pada kedua kelompok menggunakan uji Mann Whitney, diperoleh hasil uji statistik terhadap kedua kelompok pada saat pre-test nilai $p=0,221 \quad(p>0,05)$ menunjukkan tidak ada perbedaan nilai mean antara kelompok intervensi dan kelompok non intervensi artinya kondisi psikologis penderita hipertensi baik pada kelompok intervensi dan non intervensi sebelum diberikan konseling pada kelompok intervensi tidak berbeda secara signifikan. Namun setelah di berikan konseling prolanis untuk kelompok intervensi sedangkan kelompok non intervensi diberikan leaflet tentang intervensi hasilnya diperoleh nilai $p=0,000$ $(p<0,05)$ menunjukkan terdapat perbedaan yang signifikan skor kondisi psikologis antara penderita kelompok intervensi dengan non intervensi sebesar 19,2.

Untuk hubungan sosial perbandingan hasil pre-test dan post-test pada kedua kelompok menggunakan uji Mann Whitney, diperoleh hasil uji statistik terhadap kedua kelompok pada saat pretest nilai $p=0,260(p>0,05)$ menunjukkan tidak ada perbedaan nilai mean antara kelompok intervensi dan kelompok non intervensi artinya hubungan sosial penderita hipertensi baik pada kelompok intervensi dan non intervensi sebelum 
diberikan konseling pada kelompok intervensi tidak berbeda secara signifikan. Namun setelah di berikan konseling prolanis untuk kelompok intervensi sedangkan kelompok non intervensi diberikan leaflet tentang intervensi hasilnya diperoleh nilai $p=0,000 \quad(p<0,05)$ menunjukkan terdapat perbedaan yang signifikan skor hubungan sosial antara penderita kelompok intervensi dengan non intervensi sebesar 15,6.

Hasil uji statistik terhadap kondisi lingkungan perbandingan hasil pre-test dan post-test pada kedua kelompok menggunakan uji Mann Whitney, diperoleh hasil uji statistik terhadap kedua kelompok pada saat pre-test nilai $p=0,064(p>0,05)$ menunjukkan tidak ada perbedaan nilai mean antara kelompok intervensi dan kelompok non intervensi artinya kondisi lingkungan penderita hipertensi baik pada kelompok intervensi dan non intervensi sebelum diberikan konseling pada kelompok intervensi tidak berbeda secara signifikan. Namun setelah di berikan konseling prolanis untuk kelompok intervensi sedangkan kelompok non intervensi diberikan leaflet tentang intervensi hasilnya diperoleh nilai $p=0,000$ $(p<0,05)$ menunjukkan terdapat perbedaan yang signifikan skor hubungan sosial antara penderita kelompok intervensi dengan non intervensi sebesar 16,84. Hal ini disebabkan karena beda perlakuan pada kedua kelompok, sehingga pada kelompok yang hanya diberikan leaflet tidak mengalami peningkatan skor yang signifikan untuk kesehatan fisik sehingga responden masih tetap mengeluhkan kondisi yang sama seperti saat dilakukan pre-test. Hal ini sangat berbeda dengan penelitian yang dilakukan oleh Kusumaningjatin (2007) menunjukkan tidak ada perbedaan bermakna antara kelompok intervensi dan kontrol.

\section{KESIMPULAN}

Ada pengaruh Prolanis terhadap kualitas hidup penderita hipertensi terlihat pada beda skor rata-rata kesehatan fisik, kondisi psikologis, hubungan sosial dan kondisi lingkungan yang diperoleh responden saat sebelum dan sesudah intervensi. Ada perbedaan kualitas hidup penderita hipertensi sebelum dan sesudah intervensi antara kelompok intervensi dengan kelompok non intervensi terlihat pada beda skor rata-rata yang signifikan antar kedua kelompok setelah intervensi. Untuk itu perlu dilakukan studi yang sama terkait pengaruh Prolanis terhadap penyakit kronis lainnya, sebaiknya kegiatan prolanis terus dioptimalkan untuk membantu para penyandang penyakit kronis mencapai kualitas hidup yang optimal, sebaiknya kegiatan seperti ini dapat diberikan di setiap fasyankes tingkat pertama, sebagai upaya menekan jumlah pasien dirujuk ke rumah sakit, perlunya upaya yang dilakukan oleh pihak BPJS sebagai penyelenggara kegiatan Prolanis bekerjasama dengan pihak puskesmas menanggulangi bukan hanya penyakit kronis atau penyakit tidak menular lainnya, tetapi terhadap peningkatan penyakit menular.

\section{Daftar pustaka}

Abdullah, A. Z. \& M Thaha, R. 2013. Faktor Yang Berhubungan Dengan Efektifitas Terapi Hipertensi Di Puskesmas Pattingalloang Kota Makassar Tahun 2013. Diakses pada 7 Februari 2015

Adepu, R. \& Madhu, S. 2011. Influence of post discharge counseling on health outcomes in diabetic and hypertensive patients. Asian J Pharm Clin Res, 4, 28-33. Diakses pada 4 Februari 2015

Ahmad, K. 2014. Promosi Kesehatan dengan Pendekatan teori perilaku, media dan aplikasinya. Jakarta: Rajagrafindo Persada

Ambardini, R. L. \& Kes, M. Simulasi Pengelolaan Mandiri Penyakit Kronik Degeneratif Bagi Kader Yandu Lansia Desa Wedomartani, Ngemplak, Sleman. INOTEK.

Ari, S \& Danang, S. 2013. Statistik Kesehatan. Yogyakarta: Nuha Medika

Arif, D. \& Hartinah, D. 2013. Faktor-Faktor Yang Berhubungan Dengan Kejadian Hipertensi Pada Lansia Di Pusling Desa Klumpit Upt Puskesmas Gribig Kabupaten 
Kudus. JURNAL ILMU KEPERAWATAN DAN KEBIDANAN, 4, 18-34.

Chobanian, A. 2003. Joint National Committee on Prevention, Detection, Evaluation, and Treatment of High Blood Pressure. National Heart, Lung, and Blood Institute; National High Blood Pressure Education Program Coordinating Committee: Seventh report of the Joint National Committee on Prevention, Detection, Evaluation, and Treatment of High Blood Pressure. Hypertension, 42, 1206-1252.

Dans, A., Ng, N., Varghese, C., Tai, E. S., Firestone, R. \& Bonita, R. 2011. The rise of chronic non-communicable diseases in southeast Asia: time for action. The Lancet, 377, 680-689.

Dahlan Sopiyudin, 2013. Besar Sampel dan Cara Pengambilan Sampel. Jakarta: Salemba Medika

Depkes RI, 2008. Pedoman Teknis Penemuan dan Tata Laksana Hipertensi. Direktorat Pengendalian Penyakit Tidak Menular. Dirjen PP \& PL

Dinas Kesehatan Kota Makassar, 2015. Laporan Profil Dinas Kesehatan Tahun 2015

Getut, P, 2006. Panduan Lengkap SPSS Dalam Mengolah Data Statistik. Jakarta: PT Elex Media Komputindo

Glynn, L. G., Murphy, A. W., Smith, S. M., Schroeder, K. \& Fahey, T. 2010. Selfmonitoring and other non-pharmacological interventions to improve the management of hypertension in primary care: a systematic review. British Journal of General Practice, 60, e476-e488.

Gunarsa, S. D. 2007. Konseling dan psikoterapi. Jakarta: Gunung Mulia.

Jafar, N. \& Apt, M. K. 2010. B29 HIPERTENSI. Diakses pada 21 Januari 2015

Mappiare, A. 2011. Pengantar Konseling Dan Psikoterapi, Jakarta: PT. Rajawali Pers.
Morrison, F., Shubina, M. \& Turchin, A. 2012. Lifestyle counseling in routine care and long-term glucose, blood pressure, and cholesterol control in patients with diabetes. Diabetes care, 35, 334-341.

Murti, B. 2003. Prinsip dan Metode Riset Epidemiologi, Cetakan pertama, Edisi Kedua. Gadjah Mada Press, Yogyakarta.

Notoatmodjo, S. 2002. Metodologi Penelitian Kesehatan. Jakarta: Rineka Cipta

Peraturan Presiden No.12 Tahun 2013 Tentang Jaminan Kesehatan.

Peraturan Presiden RI No.72 tahun 2012 tentang Sistem Kesehatan Nasional

Program Pascasarjana Universitas Hasanuddin, 2012. Pedoman Penulisan Tesis dan Disertasi. Makassar.

PT. Askes. 2010. Buletin Info Askes edisi Mei. Jakarta Pusat : PT Askes (Persero)

Puskesmas Antang, 2015. Laporan Profil Puskesmas Antang Tahun 2015

Rahajeng $E$, Tuminah S. Prevalensi hipertensi dan determinannya di Indonesia. Maj Kedokt Indon. 2009;59(12):580-587. Diakses pada 5 Februari 2015

Riskesdas, 2013. Riset Kesehatan Dasar. Badan Penelitian dan Pengembangan Kesehatan Kementerian Kesehatan RI. Jakarta: Kemenkes RI. Diakses pada 25 November 2015

Sari, A. N., Istiono, W. \& Kes, M. 2015. Efektivitas Pelaksanaan Program Pengelolaan Penyakit Kronis (Prolanis) Dalam Penanganan Diabetes Melitus Tipe 2 Oleh Dokter Keluarga Di Kecamatan Turi, Kabupaten Sleman. Universitas Gadjah Mada.

Setiawan, Z. 2006. Prevalensi dan determinan hipertensi di pulau Jawa, tahun 2004. Kesmas Jurnal Kesehatan Masyarakat Nasional, 1.Diakses pada 5 Februari 2015 
Soekidjo, N. 2005. Metode penelitian kesehatan. Penerbit Rineka Cipta, Jakarta.

UU RI Nomor 40 Tahun 2004 Tentang Sistem Jaminan Sosial Nasional

UU RI Nomor 24 tahun 2011 Tentang Badan Penyelenggara Jaminan Sosial

Weingarten, S. R., Henning, J. M., Badamgarav, E., Knight, K., Hasselblad, V., Gano Jr, A. \& Ofman, J. J. 2002. Interventions used in disease management programmes for patients with chronic illnesswhich ones work? Meta-analysis of published reports. Bmj, 325, 925. Diakses pada 9 Februari 2015

WHO. 2004. The World Health Organization Quality of Life (WHOQOL)-BREF. Diakses pada tanggal 20 Januari 2015

Yogiantoro M, 2006, Hipertensi Esensial dalam Buku Ajar Penyakit Dalam Jilid I Edisi ke IV, FK UI, Jakarta 